\title{
Manuscritos dieciochescos desconocidos del Fondo Altamira en la Biblioteca de Ginebra
}

Unknown eighteenth-century manuscripts from the Altamira Archives at Geneva Library

José Checa Bettrán

Consejo Superior de Investigaciones Científicas

Abraham Madroñal Durán

Universitè de Genève

CESXVIII, núm. 28 (2018), págs. 221-252

DOI: https://doi.org/10.17811/cesxviii.28.2018.221-252

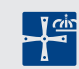




\section{RESUMEN}

En la «Collection Favre» de la Bibliothèque de Genève se custodia el «Fondo Altamira», 83 códices con unos diez mil documentos históricos y literarios, casi todos manuscritos. Contienen textos de los siglos XV al XVIII. Constituyen una pequeña parte del enorme fondo documental que en el siglo XIX pertenecía a los Condes de Altamira. Cuatro de esos 83 volúmenes contienen manuscritos literarios del Siglo de Oro y, sobre todo, del siglo ilustrado. Los autores de este artículo ofrecen aquí un catálogo de todos esos textos, centrando su atención en los relativos al Siglo XVIII. La mayor parte de este inventario corresponde a manuscritos desconocidos e inéditos: diez comedias y un gran número de composiciones poéticas de temática variada, amorosa, sátira política, religiosa, temas festivos, eventos, milagros, villancicos, sobre teatro y actores, etc.

\section{Palabras clave}

Literatura del siglo XVIII español, manuscritos literarios inéditos del siglo XVIII español, Fondo Altamira, Biblioteca de Ginebra, Collection Favre.

\section{ABSTRACT}

In the «Collection Favre» of the Bibliothèque de Genève the «Fondo Altamira» is guarded, 83 codices with some ten thousand historical and literary documents, almost all manuscripts. They contain texts from the 15th to the 18th centuries. They constitute a small part of the enormous documentary collection that belonged to the Counts of Altamira in the 19th century. Four of those 83 volumes contain literary manuscripts of the Golden Age and, above all, the Enlightenment century. The authors of this article offer a catalogue of all these texts, with a particular focus on those related to the XVIII Century. Most of this inventory corresponds to unknown and unpublished manuscripts: ten comedies and a large number of poetic compositions of varied theme, love, political satire, religious, festive themes, events, miracles, Christmas carols, theater and actors, etc.

\section{KEY Words}

Literature of the eighteenth century Spanish, unpublished literary manuscripts of the eighteenth century Spanish, Altamira Archives, Geneva Library, Collection Favre.

Recibido: 24 de abril de 2018. Aceptado. 4 de mayo de 2018.

Este trabajo se inscribe en la colaboración de sus dos autores dentro del Programa Estatal de Promoción del Talento y su Empleabilidad en I+D+i, subprograma Estatal de Movilidad del Plan Estatal de Investigación Científica y Técnica y de Innovación (PRX17/00296).

Agradecemos a la profesora Elena de Lorenzo los abundantes y valiosos datos que nos ha proporcionado para la identificación de varias entradas de este catálogo. 
En la Bibliothéque de Genève se conserva el «Fondo Altamira», unos 10.000 documentos históricos y literarios, casi todos manuscritos, que forman parte de la llamada «Collection Favre». Son 83 volúmenes — cada uno con un número de folios diferente-, con textos redactados entre los siglos XV al XVIII. Estos constituían solo una parte del enorme fondo documental que en el siglo XIX pertenecía a los condes de Altamira, quienes ante la ruina económica en que se hallaban, dispersaron, malvendieron o perdieron un riquísimo tesoro compuesto no solo por documentos sino también por libros. La biblioteca se dispersó por toda Europa, mientras que los documentos que no fueron a la basura se encuentran repartidos principalmente en Madrid (Bibliotecas Zabálburu y Valencia de Don Juan), en Londres (British Museum) y en Ginebra (Biblioteca de Ginebra).

El origen de esta rica colección documental se remonta al Conde Duque de Olivares, quien consiguió de Felipe IV dos cédulas que le autorizaban a recoger papeles de Estado y, además, «valiéndose de su omnímodo poder, obtuvo de las autoridades eclesiásticas licencia para requisar libros y manuscritos de monasterios, conventos, catedrales, colegiatas, etc., dignos por su valor artístico, antiguiedad, rareza, etc., para figurar en su biblioteca» ${ }^{1}$. Su propósito fue crear una importante biblioteca y archivo.

El núcleo de su colección estaba constituido por los archivos de las secretarías de Estado. Se apropió, así, de muchos documentos de la época de Felipe II y décadas siguientes. El conde-duque obtuvo la autorización de su rey para adueñarse de ellos con el fin de que «los tengáis en vuestro poder y los dejéis vinculados en vuestra casa, estado y mayorazgo para que anden en ella y estén guardados en sus archivos» ${ }^{2}$.

Sucesivas herencias y diferentes avatares de casamientos cruzados entre distintas casas nobiliarias fueron enriqueciendo aquella colección, que du-

1 Una exposición detallada sobre la formación y dispersión de este valioso fondo documental se encuentra en Gregorio de ANDRÉs, «La dispersión de la valiosa colección bibliográfica y documental de la Casa de Altamira», Hispania, xLVI / 164 (1986), págs. 587-635. La cita en pág. 588. Véase también Abraham MADroñal, Poesías desconocidas del Siglo de Oro recuperadas de la Biblioteca de Ginebra, Lausanne, Sociedad Suiza de Estudios Hispánicos, 2016, así como Alfredo Alvar, «Contenido y dispersión de una colección "imperial", la famosa de Altamira», en Abraham Madroñal y Carlos Mata Induráin (eds.), El Parnaso de Cervantes y otros parnasos, New York, Idea, 2017, págs. 93-129.

2 ANDRÉs, «La dispersión», pág. 90. 
rante más de dos siglos se fue reuniendo con otras hasta que, enormemente rica, acabó siendo propiedad del condado de Altamira. En efecto, tras la muerte de Olivares, aquel legado se dividió entre sus tres herederos. La colección se siguió enriqueciendo gracias a diversos casamientos (marqueses de Leganés, de Astorga, de Velada, ducados de Sessa y de Baena...). Después de muchas peripecias la colección llegó en 1711 a poder del décimo conde de Altamira. En 1797, tras unirse el solar de Montemar con Altamira «se cierra la adquisición de manuscritos y documentos, aunque otras obras impresas entraron durante el siglo XIX como consta en los catálogos de venta» ${ }^{3}$.

La disolución de este rico patrimonio se consumó con los últimos miembros de la Casa de Altamira en el siglo XIx, sobre todo con el último, José María Osorio y Moscoso, 16 Conde de Altamira, responsable de la «almoneda de su rico fondo documental histórico y su valiosa biblioteca, aunque ya anteriormente se había comenzado a dispersar el fondo librario por una primera almoneda realizada en Londres en 1824». El motivo de la dispersión fue «la catastrófica situación económica a la que llegó tan opulenta Casa que le obligó a sucesivas almonedas de sus bienes bibliográficos y artísticos» ${ }^{4}$.

Unos siete mil volúmenes de aquella biblioteca fueron vendidos en 1825 a un librero londinense, que a su vez los vendió a la Biblioteca de Edimburgo. Luego, «a partir de 1869, esparcióse la nueva entre libreros de ocasión y aficionados a antiguallas de toda clase de que del palacio de Altamira salían los legajos a montones, vendiéndose sin tino y estimación, para los usos más viles y despreciables, como tiendas y especerías», es decir, como papel de envolver u otros usos higiénicos. Además, en 1870 se hicieron tres subastas en París en las que se dispersó una parte de aquella excelente biblioteca, obras impresas y también preciosos manuscritos de los siglos XII al XV. Como afirma de Andrés, aquella enajenación de documentos valiosísimos fue bochornosa y «salpica también a los 'cultos' gobernantes de aquellos días al no impedir tal desatino perpetrado en el centro de Madrid $»^{5}$.

En conclusión, aquel enorme archivo documental fue adquirido por: 1) tenderos, 2) por el bibliotecario del Congreso don José Sancho Rayón, que operaba en nombre de la familia Zabálburu, 3) por el bibliotecario suizo Pablo Chapuy, 4) por la familia del Conde de Valencia de Don Juan, quien compró una parte tras encontrar una carta del Gran Capitán en el retrete de una tienda de comestibles... ${ }^{6}$

\footnotetext{
ANDRÉs, «La dispersión», pág. 596.

ANDRÉs, «La dispersión», pág. 598.

ANDRÉs, págs. 609, 610 y 616.

6 Andrés, págs. 617-618.
} 
El citado conde vendió en 1870 al Museo Británico cuatro lotes de documentos (comedias autógrafas de Lope de Vega y otros autores, cancioneros medievales o de los siglos XVI y XVII, etc.) y cartas de importantes personajes de la Historia de España. Sin embargo, unos 30.000 documentos quedan todavía en el Instituto de Valencia de Don Juan. Por otra parte, en el Archivo Zabálburu se conservan 264 carpetas o legajos de aquella colección.

Por último, un gran número de documentos fue a parar a Ginebra: Paul Chapuy, cónsul suizo en Madrid y, al tiempo, bibliotecario del Conde de Altamira, adquirió esos materiales, que el historiador ginebrino Èdouard Favre (18551942) compró después a sus herederos y donó a la biblioteca universitaria de Ginebra, donde aún permanecen. Sabemos que este lote está compuesto de unos 10.000 documentos, inventariados muchos de ellos por Leopold Micheli. Ese inventario fue publicado en el Bulletin Hispanique entre 1909 y 1912 $2^{7}$ son 82 volúmenes catalogados ${ }^{8}$, la mayoría de los cuales contiene documentos relativos a la Historia de España, datados entre 1435 y finales del siglo XVIII. Solo los volúmenes 77, 78, 79 y 80 contienen documentos literarios ${ }^{9}$, de los siglos XVI al XVIII, la inmensa mayoría manuscritos; muy pocos son impresos. Micheli enumera el contenido de los volúmenes históricos con mayor precisión y detalle que los literarios, descritos estos de manera muy sumaria: «de los códices LXXVII y LXXVIII se limita a dar exclusivamente el título de las comedias que los componen. Pero todavía es menor la información que aporta cuando se refiere a los códices poéticos» ${ }^{10}$, los números 79 y 80 , presentados con un escueto «Recueil de pièces de vers» y poco más.

Inventariamos aquí de forma detallada los cuatro volúmenes literarios, tomando como base el catálogo recientemente publicado por Madroñal en su libro citado. Mantenemos en letra pequeña y coloreada los documentos pertenecientes al Siglo de Oro, en los que Madroñal centró su libro. Relacionamos en letra de mayor tamaño los pertenecientes al siglo ilustrado, a los que prestamos una especial atención, ampliando y detallando la información facilitada antes por Madroñal. La práctica totalidad de los manuscritos inventariados son desconocidos. Nuestra intención es transcribir y editar en próximas publicaciones los textos inéditos más interesantes.

7 Léopold MicheLI, «Inventaire de la Collection Édouard Favre», Bulletin Hispanique, t. 1 (19091912: 1909), págs. 295-322; t. 12 (1910), págs. 49-70, 140-162 y 317-326; t. 13 (1911), págs. 61-74 y 195204; t. 14 (1912), págs. 77-95.

8 Hoy sabemos que existe un volumen 83, que hemos consultado en Ginebra y que solo contiene documentos históricos, ninguno literario.

9 Los compradores del British Museum estaban más interesados que Chapuy en los códices literarios.

10 Madroñal, Poesías desconocidas, pág. 14. 
Como se verá en el catálogo que figura a continuación —en el que actualizamos grafías, acentuación y puntuación - los volúmenes 77 y 78 contienen diez comedias, todas del siglo XVIII, cuyo primer examen indica que son desconocidas e inéditas: hemos comprobado que sus títulos no aparecen en ninguno de los principales repertorios sobre el teatro o carteleras consultadas ${ }^{11}$. Se trata de comedias de magia, de enredo, de figurón, palatinas y de capa y espada. Confiamos en que su posterior estudio pueda permitirnos fecharlas con la mayor precisión posible y, quizás, atribuirlas a algún autor de la época. En cualquier caso, su catalogación contribuirá a profundizar en el conocimiento del teatro de aquellos años y a enriquecer el patrimonio literario español.

Los volúmenes 79 y 80 contienen, además de unos pocos textos en prosa y algunos impresos, un gran número de poesías manuscritas en diversas formas estróficas y sobre asuntos muy variados: amor, política, religión, el teatro y los actores, personajes de la nobleza, temas festivos, eventos, desgracias, milagros, villancicos y sobre cuestiones sociales en general. Actualmente estamos preparando la edición de una selección de estos poemas.

Catálogo (volúmenes 77, 78, 79, 80)

\section{VOLUMEN 77}

Folios 1-390

Contiene cinco comedias manuscritas y un poema en 35 octavas (letra del siglo XVIII).

1: Comedia intitulada No hay fuerza contra el gusto, contra la hermosura armas, resistencia contra amores ni amor contra la palabra

Folios 1-62v

Dividida en tres jornadas: $1 .^{a}$ : ff. $1-21 / 2 .^{a}$ : ff. $21 v-41 v / 3 .^{a}:$ ff. $42-62 v$.

11 Hemos consultado la Bibliografía de Autores españoles del siglo XVIII, de Francisco Aguilar Piñal, la Cartelera teatral madrileña del siglo XVIII (1708-1808), de René Andioc y Mireille Coulon, el Catálogo de autores teatrales del siglo XVIII, de Jerónimo Herrera Navarro, el Catálogo biográfico y bibliográfico del teatro antiguo español, de Cayetano Alberto de la Barrera, el Catálogo bibliográfico y crítico de las comedias anunciadas en los periódicos de Madrid desde 1661 hasta 1819, de Ada M. Coe, así como las Traducciones españolas del teatro francés (1700-1835) de Francisco Lafarga y el Catálogo Colectivo del Patrimonio Bibliográfico Español (CCPB). 
Hablan en ella: Astolfo, rey de Gocia; Filipo, rey de Suevia; Arnesto, barba; Alberto, gracioso; Licenia, duquesa de Rusia; Laura, su prima; Silvia, dama; Soldados, acompañamiento y música.

\section{Comienza:}

Con el estruendo de algunos tiros, cajas y clarines salen Astolfo y Alberto. Astolfo: Cesen las bélicas salvas...

Termina:

Todos: Y aquí tengan nuestras faltas, noble auditorio, perdón.

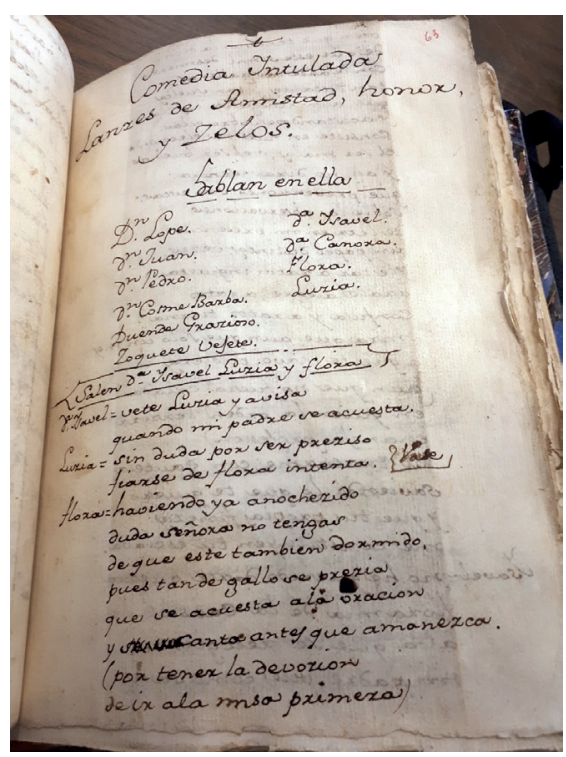

2: Comedia intitulada Lances de amistad, honor y celos

Folios 63-130

Dividida en tres jornadas: $1 .^{\mathrm{a}}:$ ff. $63-83 \mathrm{v} / 2 .^{\mathrm{a}}:$ ff. 84-108v / 3.. $:$ ff. 108v-130.

Hablan en ella: don Lope; don Juan; don Pedro; don Cosme, barba; Duende, gracioso; Zoquete, vejete; doña Isabel; doña Canora; Flora; Lucía.

Comienza:

Salen doña Isabel, Lucía y Flora

Doña Isabel: Vete, Lucía, y avisa... 
Termina:

\section{Todos:}

Y aquí acaba la comedia, perdonad sus muchos yerros.

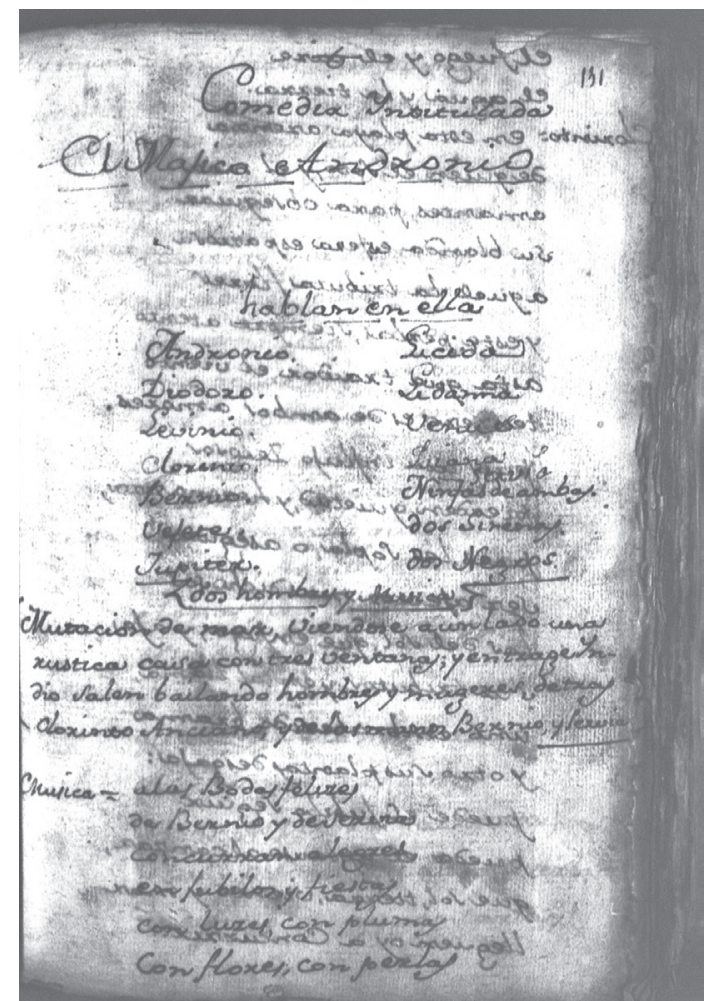

\section{3: Comedia intitulada El mágico Andronio ${ }^{12}$}

Folios 131-193

Dividida en tres jornadas: 1. ${ }^{a}$ :ff. 131-150v / 2. ${ }^{\mathrm{a}}$ : ff. 151-172v / 3. ${ }^{\mathrm{a}}$ : ff. 173-193.

Hablan en ella: Andronio; Diodoro; Levinio; Clorinto; Bernio; Vejete; Júpiter; Lícida; Lidamia; Venus; Diana; Servia; ninfas de ambas; dos sirenas; dos negros.

12 Inés Morandi está realizando en la Universidad de Ginebra una tesis doctoral, dirigida por el profesor Madroñal, en la que editará esta comedia. 


\section{Comienza:}

Dos hombres y música. / Mutación de mar, viéndose a un lado una rústica casa con tres ventanas; y en traje indio salen bailando hombres y mujeres, detrás Clorinto anciano, y de las manos Bernio y Servia.

Música: A las bodas felices...

Termina:

Clorinto: Porque con razón se diga.

Todos: Porque con razón se cuente

Unos cantando y otros representando:

Que Diana no se enoja.

Que Venus no se ofende.

de los castos amores,

de los justos desdenes.

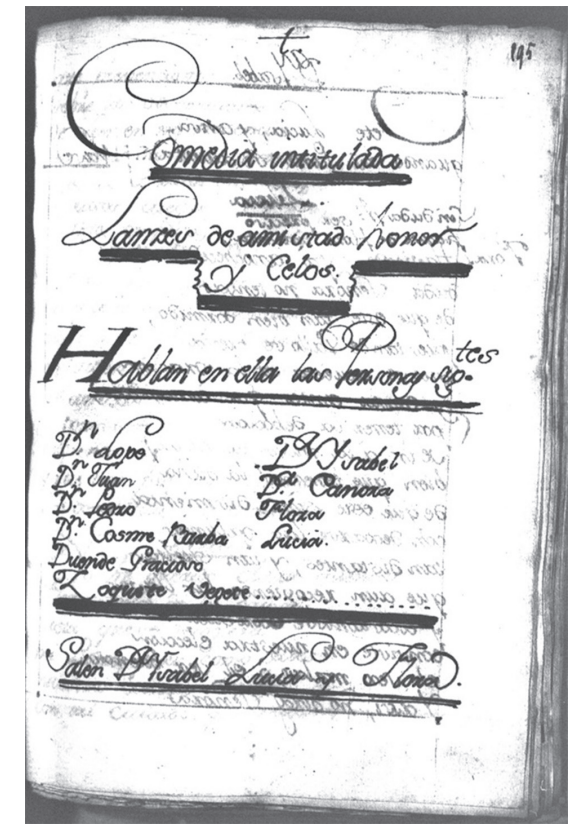

4: Comedia intitulada Lances de amistad, honor y celos [es la misma que la número dos; escrita con letra distinta]

Folios 195-312

Dividida en tres jornadas: $1 .^{\mathrm{a}}$ : ff. 195-228v / 2. ${ }^{\mathrm{a}}$ : ff. $228 \mathrm{v}-272$ / 3. ${ }^{\mathrm{a}}$ : ff. $272 \mathrm{v}-312$. 
Hablan en ella las personas siguientes: don Lope; don Juan; don Pedro; don Cosme, barba; Duende, gracioso; Zoquete, vejete; doña Isabel; doña Canora; Flora; Lucía.

Comienza: Salen Isabel, Lucía y Flora

Doña Isabel:

Vete, Lucía y avisa

cuando mi padre se acuesta.

Lucía:

Sin duda por ser preciso

fiarse de hora intenta.

Termina:

Todos:

Y aquí acaba la comedia, perdonad sus muchos yerros.

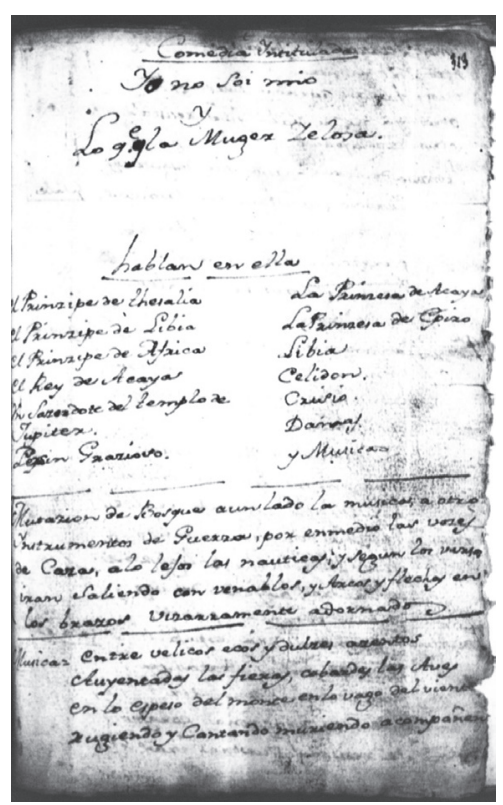

5: Comedia intitulada Yo no soy mío y lo que es la mujer celosa

Folios 313-380

Dividida en tres jornadas: 1. ${ }^{\mathrm{a}}$ : ff. 313-335 / 2. ${ }^{\mathrm{a}}$ : ff. 337-359v / 3. ${ }^{\mathrm{a}}$ : ff. 361-380. 
Hablan en ella: el príncipe de Tesalia; el príncipe de Libia; el príncipe de África; el rey de Acayas; un sacerdote del templo de Júpiter; Persín, gracioso; la princesa de Acayas; la princesa de Epiro; Libia; Celidón; Crisio; damas y música.

Comienza: Mutación de bosque a un lado, la música a otro. Instrumentos de guerra, por en medio las voces de caza, a lo lejos las náuticas; y según los versos irán saliendo con venablos y arcos y flechas en los brazos bizarramente adornados.

Música:

Entre bélicos ecos y dulces acentos.

Termina:

Todos:

Y en otra segunda parte

tendrá fin esta mentira.

6: Octavas sobre el estreno en la casa de la Marquesa de Astorga de la comedia de Bances de Candamo Quién es quien premia al Amor ${ }^{13}$

Folios 383-390.

Son 35 octavas.

Comienzo de la Octava I:

Sagrado Apolo, centro soberano,

De primores y ciencias peregrino,

Protector de mi numen, con que ufano

Suele lograr victorias del Destino;

Final de la última octava:

Busca el silencio y en su templo queda

Pidiendo que el perdón se te conceda.

Finis coronat opus. [Firmado por:] Zerro.

\section{Volumen 78}

Folios 1-354

Contiene 5 comedias manuscritas y un «poema épico» (letra del siglo XVIII).

13 Publicadas por Abraham Madroñal, Poesías desconocidas, págs. 269-279, quien considera que su fecha de composición podría ser 1689. 


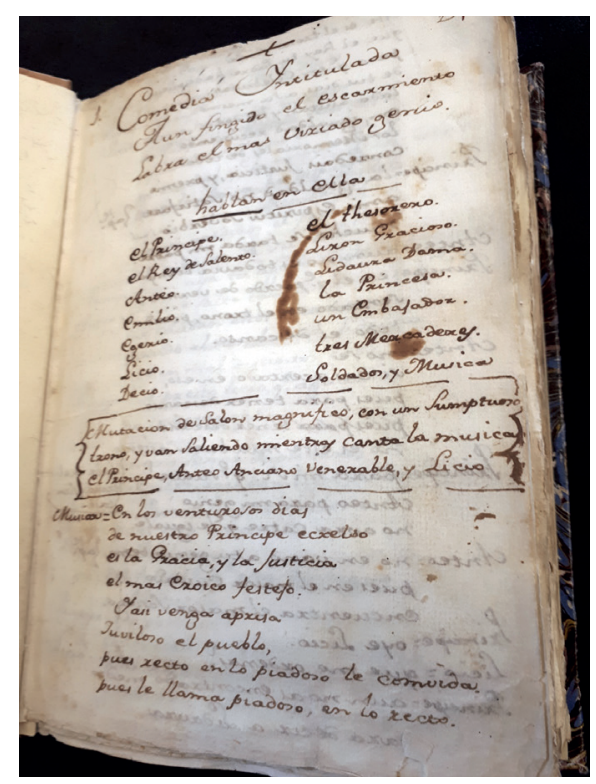

\section{1: Comedia intitulada Aun fingido el escarmiento labra el más viciado genio}

Folios 1-69

Dividida en tres jornadas: $1 .^{\mathrm{a}}:$ ff. $1-23 \mathrm{v} / 2 .^{\mathrm{a}}$ : ff. $25-48 \mathrm{v} / 3 .^{\mathrm{a}}$ : ff. 49-69v.

Hablan en ella: el príncipe; el rey de Salento; Anteo; Emilio; Egerio; Licio; Decio; el tesorero; Lirón, gracioso; Lidaura, dama; la princesa; un embajador; tres mercaderes; soldados y música.

\section{Comienza:}

Mutación de salón magnífico, con un sumptuoso trono, y van saliendo, mientras canta la música, el Príncipe, Anteo, anciano venerable, y Licio.

\section{Música:}

Con los venturosos días

de nuestro Príncipe excelso,

es la Gracia y la Justicia

el más heroico festejo.

Y así venga aprisa

jubiloso el pueblo,

pues recto en lo piadoso le convida,

pues le llama piadoso, en lo recto. 


\section{Anteo:}

Este es el trono, señor,

que el Rey tu padre ha dispuesto

para que en celebridad

de tus días, a su mesmo

lado asistas, y los dos

con igualdad recibiendo...

Termina:

\section{Lirón:}

Y aquí acaba la comedia

con todas sus boberías,

y si esta logra el aplauso,

no faltará quien escriba.

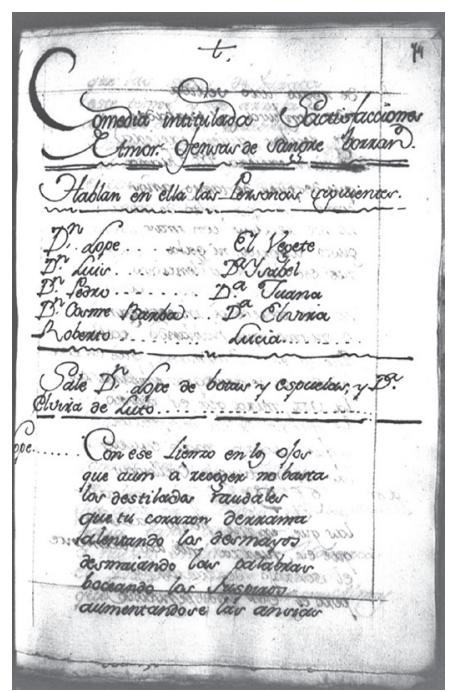

2: Comedia intitulada Satisfacciones de amor ofensas de sangre borran ${ }^{14}$

Folios 74-138

Dividida en tres jornadas: 1. ${ }^{\mathrm{a}}$ : ff. 74-98 / 2. ${ }^{\mathrm{a}}$ : ff. 99-119 / 3. ${ }^{\mathrm{a}}$ : ff. 119-138v.

14 Véase Epicteto Díaz NaVArro, «Unas notas a la comedia anónima Satisfacciones de amor ofensas de sangre borran (c. 1760)», en Abraham Madroñal y Carlos Mata Induráin (eds.), El Parnaso de Cervantes y otros parnasos, New York, Idea, 2017, págs. 157-170. 
Hablan en ella las personas siguientes: don Lope; don Luis; don Pedro; don Cosme, barba; Roberto; El vejete; doña Isabel; doña Juana; doña Elvira; Lucía.

\section{Comienza:}

Sale don Lope de botas y espuelas y doña Elvira de luto

Lope:

Con ese lienzo en los ojos,

que aun a recoger no basta

los destilados raudales

que tu corazón derrama,

alentando los desmayos,

desmayando las palabras,

voceando los suspiros

aumentándose las ansias

Termina:

Salen Lucía y el vejete de la mano.

Lucía:

Aquí estoy con mi marido

Roberto:

Por el chasco que te llevas

me alegro del que recibo

y aunque no haya quien lo diga

digo por todos que Víctor.

\section{3: Comedia intitulada Lo que son duendes del mundo}

Folios 139-206

Dividida en tres jornadas: $1 .^{a}$ : ff. 139-161 / 2. ${ }^{a}$ : ff. $161 v-184 v / 3 .^{a}:$ ff. 185-206.

Hablan en ella:

don Félix de Avendaño; don Pedro Contreras; don Juan de Avendaño; don Cirilo Lanza, figurón; don Alonso Guzmán, barba; Zampatortas, gracioso; doña Clara de Guzmán; doña Beatriz de Guzmán; doña Isabel de Avendaño; Lucrecia, criada; Quiteria, criada; otras dos criadas.

Comienza:

Salen don Félix de Avendaño, de botas y espuelas, y don Pedro de Contreras. 
Don Pedro:

Otra vez y otras mil veces

Don Félix os doy los brazos

Don Félix:

Ellos os den testimonio

de mi amistad

Don Pedro:

Y mi llanto

os acredite la mía

antes que rompan los labios

Termina:

Todos:

Que estos son duendes del mundo

fomentados las más veces

del amor, y nadie crea

que hay en el mundo otro duende.

4: Comedia intitulada obligado de tres damas, por no ofender a ninguna, a todas tres engañarlas

Folios 207-261v

Dividida en tres jornadas: 1. : ff. 207-224 / 2. ${ }^{\text {a }}$ : ff. 225-241v / 3. ${ }^{\text {a }}$ :ff. 243-261v.

Hablan en ella: Anfión; Coidroas; Estratón; Celidón; Botín; el general; Fílida; Deidama; Celida; Arcida; soldados; música.

Comienza:

Salen Anfión, Celidón, Botín y Soldados

Anfión:

Esto ha de ser.

Celidón:

Ya que sea

y que a tu gusto, señor,

no puede haber resistencia

cuando tantas prevenciones

de naves, armas y gente

ocupan el mar: dinos

solamente dónde vas, 
porque si el hado feroz

se declara contra ti...

Termina:

Botín:

Así todos obligados

engañan para servir,

merezcan perdón y aplauso

que es el mejor fin.

\section{5: Comedia intitulada La mágica de Ceilán ${ }^{15}$}

Folios 263-329

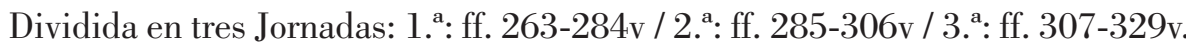

Interlocutores: Croante; Cerón; el rey; Coquín, gracioso; Benete, vejete; Eumarfile; Ismenia; Libia; damas que hacen los 4 elementos; Proserpina y Apolo; música, acompañamiento y soldados.

\section{Comienza:}

Descúbrense las murallas de Ceilán y por una sumptuosa puerta saldrán cantando todas las damas delante del Rey y acompañamiento lucido, y por un lado Croante, Cerón, Coquín, Benete y soldados al son de instrumentos marciales.

Música:

Enhorabuena venga

quien honra su patria

venciendo de Tiro

la infiel arrogancia,

y así en dulces ecos

y bélicas salvas

Termina:

Benete:

Y por ser tarde se deja

lo demás para otra parte

en donde las dos doncellas

15 Será estudiada y reproducida en la citada tesis doctoral de Inés Marandi, dirigida por el profesor Abraham Madroñal. 
que han quedado con el nombre

se casen; y en tal idea...

Todos y música:

Eumarfile y Croante

para asombro de Persia

lidiando sin lidiar

vencerán sin que venzan. FINIS

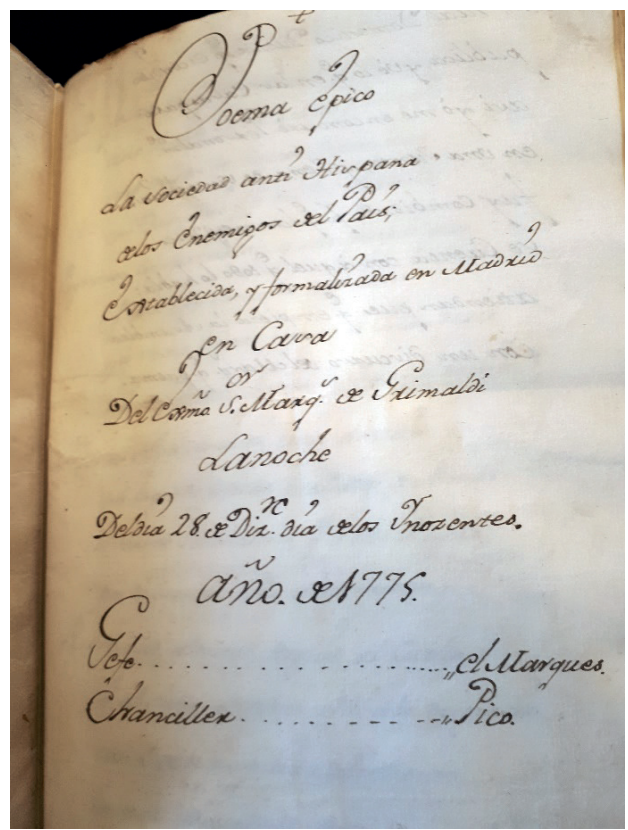

6: Poema épico La sociedad anti Hispana de los enemigos del país, establecida y formalizada en Madrid en casa del Excmo. Sr. Marqués de Grimaldi la noche del día 28 de Diciembre, día de los Inocentes. Año de $1775^{16}$

Folios 331-354v

Jefe: El Marqués / Chanciller: Pico / Comienza: «Cual doméstico duende que escondido / publica, y ve lo que en las casas pasa».

16 Este manuscrito no figura en la Bibliografía de Aguilar Piñal, que sí registra (tomo Ix, Anónimos I, págs. 745-746) otros seis manuscritos con este mismo título, cuatro en la Biblioteca Nacional, uno en la Biblioteca Municipal de Madrid y uno en la Biblioteca de Temas Gaditanos de Cádiz. 
Es una sátira contra Campomanes, Grimaldi y otros ilustrados, criticados por su adhesión a las Sociedades de Amigos del País, y concretamente por la fundación de la de Madrid ${ }^{17}$.

\section{VOLUMEN 79 18}

Folios 1-396

Poesía impresa ${ }^{19}$

1. Juan Pellicer, Demostración afectuosa en la muerte de don Luis Méndez de Haro (1651 [pero 1661]). Impreso. 4 hs. Comienza: «Qué dolorosa armonía...», ff. 1-5v.

2. Luis Nieto, Romance al excelentísimo señor duque de Aveiro, habiendo salido con una cuadrilla en la máscara que se celebró en esta Corte en 22 de diciembre el feliz nacimiento del Príncipe nuestro señor (1661). Impreso. 4 hs. Comienza: «Qué noble concurso es este...», ff. 6-8.

3. Melchor Zapata, Relación de la real máscara que se corrió a sus Magestades en la plaza de Palacio en 22 de Diciembre de 1661 (1661). Impreso. 8 hs. Comienza: «Dedicatorias no piensa...», ff. 9-16.

4. Villancicos que se cantaron en la santa iglesia catedral de Málaga (1662). Impreso. 4 hs. «Cierra España, cierra España...», ff. 17-21.

5. Soneto con el motivo del cumpleaños del excelentísimo señor Marqués de Mondéjar, mi señor; hace preferente D. Manuel Antonio de Jaureguizarra su buena ley dedicando a los pies de su Ama y Señora el siguiente soneto (c. 1750). Impreso, 1 h.: «Dichosos años viva con aumento...», f. 21.

17 Analiza el poema Elisa Martín-VALdePEÑas YAGÜE, Ilustrados, afrancesados y liberales: la Real Sociedad Económica Matritense de Amigos del País durante la Guerra de la Independencia, Madrid, UNED (Tesis doctoral), 2015, págs. 230-231.

18 Los volúmenes 79 y 80 no fueron inventariados por Micheli. Abraham Madroñal realizó en su libro citado un inventario del contenido de los volúmenes 77 al 80. Como hemos avanzado, tomamos aquí como base ese inventario, incluidas las entradas relativas a textos del Siglo de Oro, que relacionamos en tinta más clara que la usada para las correspondientes al siglo XvIII. Naturalmente, en nuestro inventario ampliamos, puntualizamos y desarrollamos las entradas correspondientes al siglo ilustrado.

19 Las composiciones 1 a 8, impresas, se conservan en forma de pliego suelto. 
No hallamos testimonio de otros ejemplares; sí de otros poemas de circunstancias de Antonio de Jaureguizarra: uno dedicado al propio Nicolás María López de Mendoza, marqués de Mondéjar, con motivo de la llegada al trono de Carlos III (datado, por tanto, en 1759); y otro redactado con motivo de la boda de Pedro de Alcántara, duque de Híjar (producida en 1765). En el primero se dice criado del marqués de Mondéjar; en el segundo, secretario y contador ${ }^{20}$.

6. Rimas lacónicas contra calmucos antiguos y modernos, a la total futura expulsión de la herejía del Británico Reyno, por la feliz expedición del Christianísimo; y progresos del pretendiente Carlos Estuard en Escocia (1745). Impreso, 2 hs.: «Comedia la vida humana / dijo Henrique Octavo que era», f. 22-22v. [Hay copia en el volumen 80, n. $\left.^{\circ} 12\right]$.

Con el título de Décimas [no Rimas] lacónicas se conservan diversos ejemplares. Aguilar Piñal localiza un impreso en la Biblioteca de la Universidad de Zaragoza (vol. Ix, ref. ${ }^{\text {a }}$ 1.513); y el CCPB, dos en la Biblioteca Pública del Estado en Huesca y en la Biblioteca Pública del Estado en Toledo. Hay otra en la BNE (MSS/3.929 (H.134)), donde también se conserva copia manuscrita del poema (MSS /18.285): Ensaladilla de varios papeles (h. 157r-161v).

7. Luis Francisco de Asís Sánchez de Baena, En las fantasías de un sueño felicitó don [...] a doña Luisa de Borbón, princesa de Asturias. Romance heroico. Impreso, 4 hs.: «Anoche, oh gran señora, tributando», ff. 23-27.

En la BNE (vE/1191/15, 6 h.) se conserva impreso junto al Romance endecasylabo, en el que se despide de las Musas para siempre / Don Luis Francisco de Assís Sanchez de Baenna [...]; y suplica a los que leyeron sus poesías perdonen las faltas ó escándalo que pueden haver notado en ellas (2 h. $)^{21}$. Constan los datos de impresión en el colofón: Madrid, Joachin Ibarra, 1768. Era princesa de Asturias desde su matrimonio con el futuro Carlos IV, en 1765.

20 BNE (VE/330/4): Lealtad española, metricos ecos y canoras voces que con motivo de la exaltación al trono de nuestro cathólico monarca D. Carlos Tercero y su deseada quanto feliz llegada à esta Corte consagra y dedica al excmo. señor D. Nicolás María Iñigo Lopez de Mendoza, \&c. Marqués de Mondejar ... / su criado Don Manuel Antonio de Jaureguizarra, Madrid, en la Imprenta de D. Gabriel Ramírez [s. a.]; BNE (ve/418/68): Metrico, alegre, humilde epitalamio de un reverente afecto producido [..., s. l., s.e., s. a.]. Ambos en Aguilar Piñal, Bibliografía de autores del siglo XVIII, vol. IV, ref. a 4.727 y 4.728

${ }^{21} \quad$ Aguilar Piñal, Bibliografía de autores del siglo XVIII, vol. viI, ref. a 3.413. 
Dos años después se publicaron las Poesías varias que en diferentes metros escribió don..., comendador de Sta. María de Bouzela en la Orden de Cristo. Las que pudo recoger y publica Corinda, en agradecimiento de los saludables avisos que la dio en su Romance exortivo (Madrid, Antonio Pérez de Soto $)^{22}$.

8. Romance satírico (s. XVIII). Impreso, 2 hs.: «Todo fiel cristiano...», ff. 27-28.

Poesía manuscrita

9. Lázaro Loredano, Rime diverse, nelle Progressi, Felicità et Grandezze dell'Illustrissima e Eccelentissima Casa de Alba, 1668 [en italiano]. Precede un prólogo firmado por el autor, ff. 30-84.

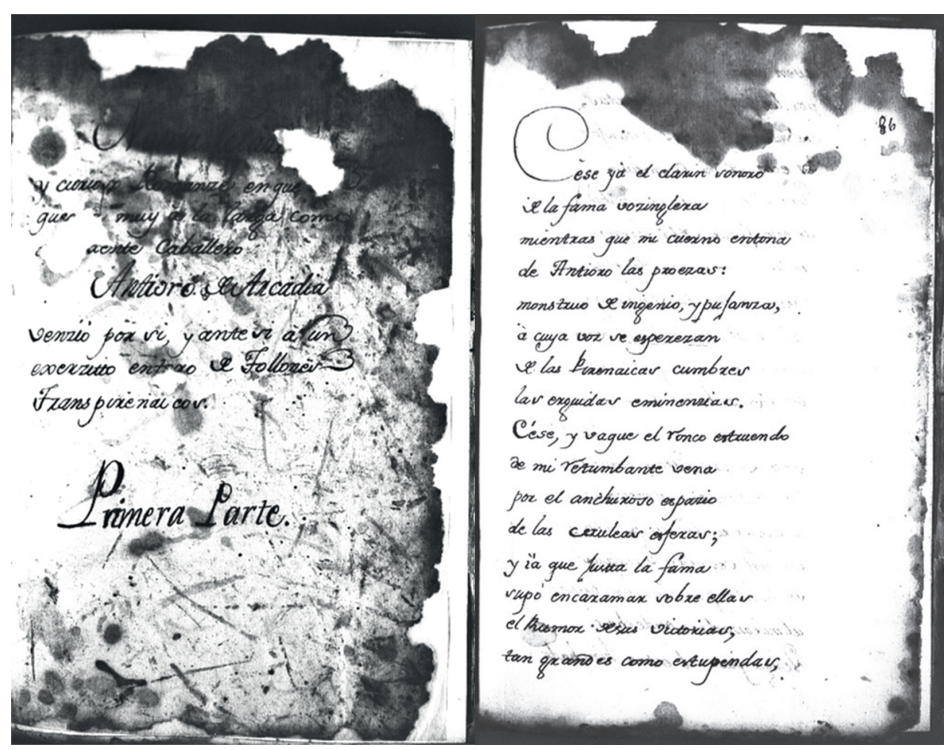

10. [Gaspar Melchor de Jovellanos]: Nueva relación y curioso romance en que [se cuenta cómo el] caballero Antioro de Arcadia venció por sí y ante sí a un

22 Sobre el autor y el juicio negativo que de su poesía realiza Ignacio de Hermosilla como censor de la Real Academia Española, que las estima «escrito inútil», puede consultarse Elena de Lorenzo ÁlvarEz, «Notas sobre la actividad censora de la Real Academia Española en el siglo XVIII», en Fernando Durán (coord.), Instituciones censoras: nuevos acercamientos a la censura de libros en la España de la Ilustración, Madrid, Consejo Superior de Investigaciones Científicas, 2016, págs. 199-241. 
ejército entero de follones transpirenaicos. Primera parte (s. XVIII): «Cese ya el clarín sonoro...», ff. 85-92 $\mathrm{v}^{23}$.

11. Diferentes poemas anónimos (s. XVIII), ff. 95-98.

- A la Comedia de Esplandián: «De bote en bote el corral...», f. 95.

- Estado de los Príncipes de la Europa. Soneto: «Inglaterra se cansa en hacer cocos...», f. 96.

— Soneto [sobre las cómicas]: «Que haga bien un zapato al zapatero...», f. 97.

— «Cuando tus días festeja...», f. 98.

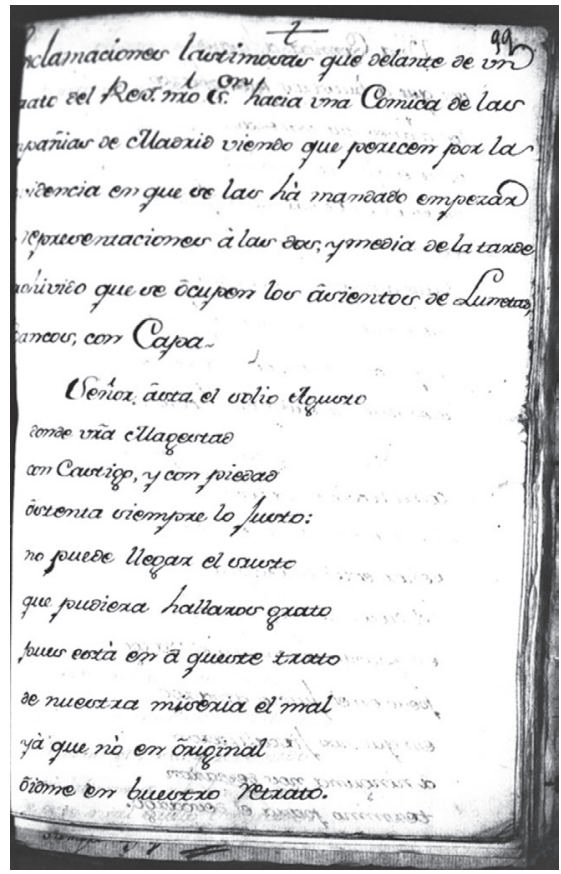

12. Reclamaciones lastimosas que delante de un retrato del Reverendísimo Señor [el rey] hacía una cómica de las compañías de Madrid viendo que perecen por la Providencia en que se las ha mandado empezar las representaciones a las

23 Se trata del «Romance I» de Jovellanos que José Miguel Caso González, a partir de otro manuscrito, editó en Gaspar Melchor de Jovellanos, Obras Completas. Tomo 1. Obras Literarias, ed. de José Miguel Caso González, Oviedo, Centro de Estudios del Siglo XVIII, 1984, págs. 202-210. 
dos y media de la tarde y prohibido que se ocupen los asientos de Lunetas, Bancos, con capa (s. XVIII): «Señor, hasta el solio agusto [sic]...»; ff. 99-105v.

Se conservan dos copias manuscritas en la BNE, como Exclamaciones lastimosas que delante de un retrato del Rey [...]. En el Mss/12.951/44 (ff. 155-160) se atribuye a Antonio Valladares; y en el Mss /10.912 (ff. 32v-41), que forma parte de la Biblioteca del Duque Osuna (t. XXVII), el título indica: Exclamaciones lastimosas que delante de un retrato del Rey hacía una cómica de la Compañía de Guerrero.

13. Poemas sobre varios asuntos (s. XVIII), ff. 107-159:

- Voz poética de un desapasionado Ingenio en asunto al ocho por ciento arbitrado sobre el Estado Eclesiástico: «Ya de Hacienda, ministros, / estad con el ojo alerta...», ff. 107-108.

— «Amando mi fiel deseo...», f. 109.

- Desahogo que hace un Amarillo Capricho en décima siguiente. Y glosa de ella por un aficionado Monsieur (contra don Mauricio Dubanton [sic]). Décima: «Es la casa de Mauricio / execrable anfiteatro...», ff. 110-112v.

- De las locuras de amor...», ff. 114-115.

- Definición de la compañía [del cómico] Parra: «Llegan las tres de la tarde...», ff. 116-122.

— «Por un superior precepto...», f. 126.

— Seguidillas: «En cuanto Hespaña toda feliz se extiende...», f. 128.

— «Apenas el horizonte...», f. 130.

- Décimas sacadas a La Pichona [alcahueta] y sus aliados celebrando los azotes que la dieron en la corte: «Para enseñar a tratar...», ff. 134-135.

Los amoríos y pleitos de la actriz María Teresa Palomino dieron lugar a muchas coplas. Se conserva copia manuscrita en la BNE: Décimas a los azotes celebrados, que dieron en esta Corte a la Pichona, comedianta: «Para enseñarte a tratar / con respeto a la grandeza» [Mss/10.951(h. 56v-60v)] MSS/14.015/4/5.

— Seguidillas: «Pintar quiero, señores...», ff. 136-138.

- Epitafio a Tamariz, que quedó muerto ensayando la contradanza en el cuarto del príncipe: «No prosigas, detente y si el amago...», ff. 140142. 
— «Considérote enfadado...», f. 142.

- Glosa al pie: «Por qué vendiste las chupas...», f. 144.

— Seguidillas: «A este pobre Atanasio...», f. 146.

— Seguidillas: «No creí, señor mío....», f. 148.

- Carta en prosa que incluye un poema: «Pues te precias de atento...», f. 150 .

— Al señor don Juan González. Décimas: «Mis faltas has publicado...», f. 152.

- Respuesta a las décimas de don Atanasio Villalobos: «El martes muy descuidado...», ff. 154-159.

14. A las bodas del conde de Fuentes con la de Huéscar (s. XVIII): «Al alba, cierto día señalado...», ff. 160-161.

15. Poema (s. XVIII): «El amor verse desea...», ff. 162-163.

16. Carta a don Atanasio Villalobos; en prosa; incluye el poema: «Salí de Madrid gozoso...», ff. 165-169.

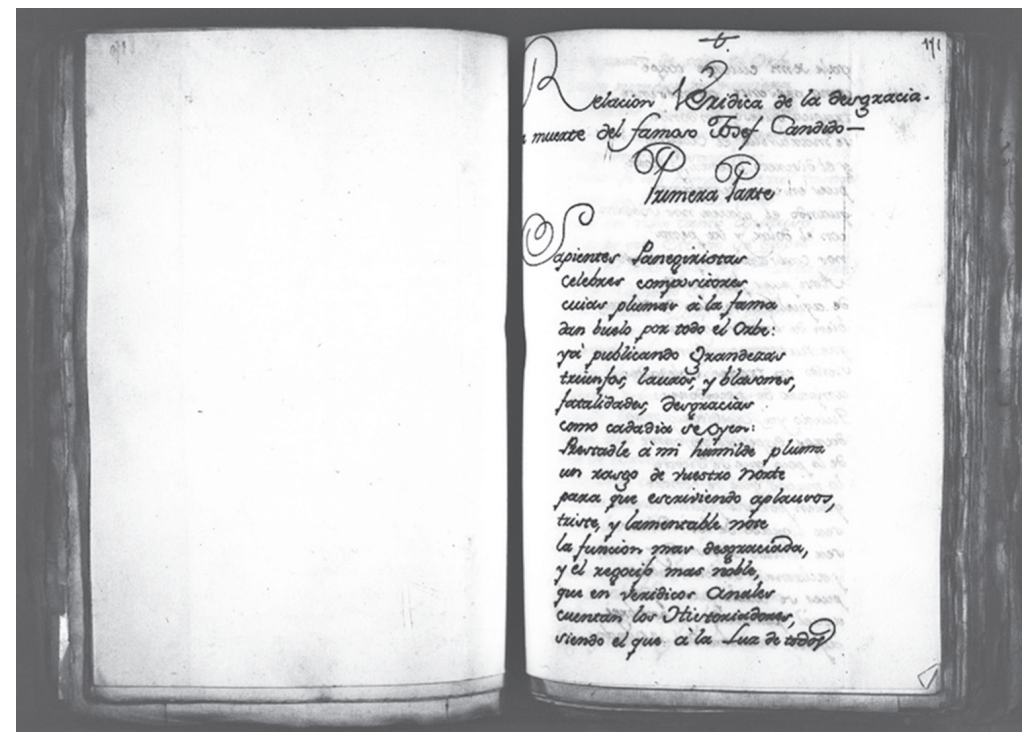

17. Relación verídica de la desgraciada muerte del famoso Josef Cándido [torero]. Primera Parte, ff.171-174v. Segunda Parte, ff. 175-178 [c. 1771]: «Sapientes panegiristas...», ff. 171-178. 


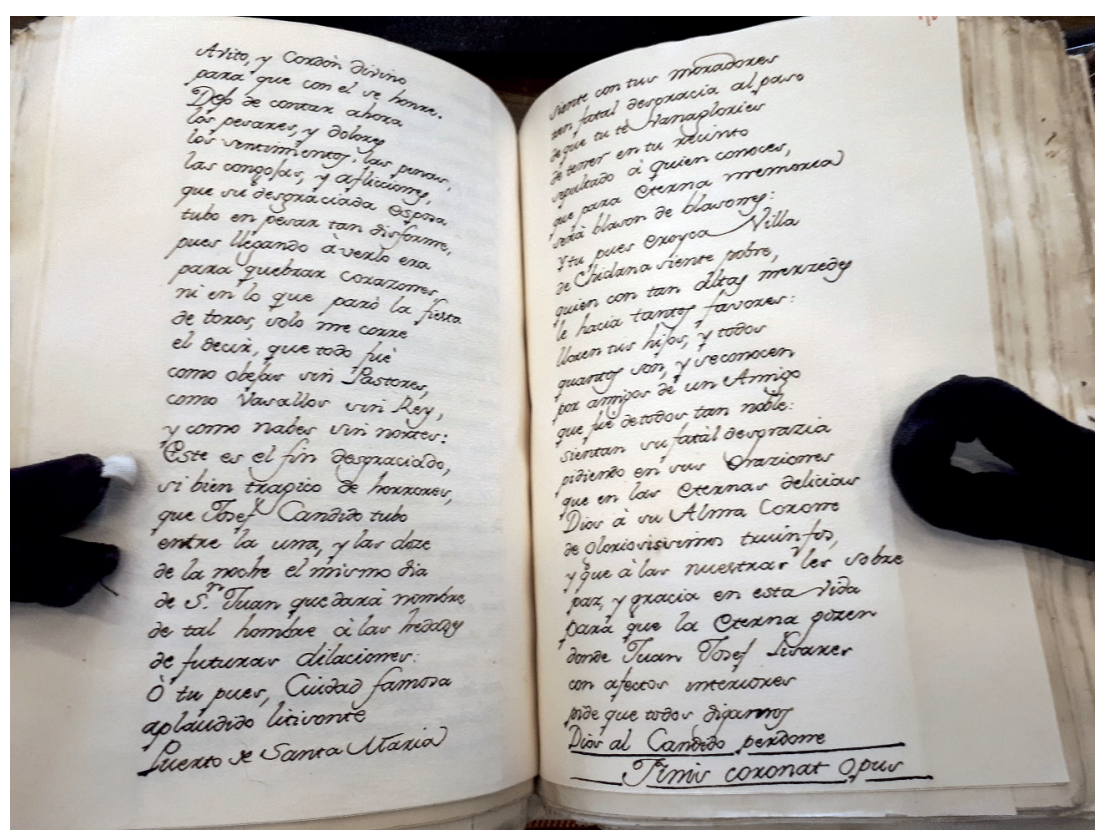

18. Fragmento de la comedia La verdad y el tiempo en tiempo [atribuida a Antonio de Zamora, 169642 ], ff. 179-187: «Estos no hablarán palabra», f. 181; incluye un romance relacionado que empieza «Mi señor don Juan Tomás», f. 186. [Falta el primer cuadernillo]. [Otra copia, completa, en la BNE, MSS 3.926].

19. Escena cómica que representa el tiempo [en el trágico] teatro de la corte, con alegorías (fines s. XVII), ff. 188-199v. [Teatro satírico contra el rey y los principales gobernantes]. «Dormida y postrada yace...», f. 189.

20. Romance satírico «Camino de Carabanchel, Perico y Marica hablan en él» [se fecha en 1690]: «A Carabanchel», ff. 199v-228.

21. Reflexiones airadas contra Perico y Marica: «De Carabanchel», ff. 221228.

22. Fantasía de don Fernando de Valenzuela y sueños en la prisión [romance del tiempo de Carlos II, 1677]: «A los rayos de una luz...», ff. 228v-234v.

24 Cayetano Alberto de la BARRERA, Catálogo biográfico y bibliográfico del teatro antiguo español, Madrid, Imprenta y Estereotipia de M. Rivadeneyra, 1860, entrada ZamorA. 
23. Decreto del rey y memorial (1677); [prosa], f. 234v.

24. Desengaño del almirante de Castilla, estando desterrado en Rioseco: «Ea verdad contra el gusto...», f. 235.

25. Copia de un memorial que el Reino de Aragón dio al duque de Orleans, año de 1707 [prosa], f. 238.

26. Copia de un memorial que el Reino de Aragón dio al rey Nuestro Señor Felipe V el año de 1707 [prosa], ff. 241-244.

27. Copia de un papel anónimo al señor rey Felipe V [prosa], f. 244v.

28. Redondillas de nuestro poeta Cartagena: «Mi vida vive muriendo...», f. $245 \mathrm{v}$.

29. Canción en verso heroico (s. XVIII): «Mientras, señor, que en el excelso monte...», ff. $245 \mathrm{v}-257 \mathrm{v}$.

30. Carta, romance y aviso a Don Athanasio Villalobos [prosa]. Incluye poemas varios (s. XVIII), ff. 259-262: «Amigo Villalobos», f. 259v.

31. Coplas a la célebre entrada de nuestra querida hernana la madre María Trinidad (s. XVIII): «Si celebramos acordes...», f. 263.

32. Poema suelto (s. XVIII): «Quien vuestra flor escogió...», f. 265.

33. A la entrada del marqués de Astorga (s. XVII): «Entraste oh sol, hiriendo con tu luz...», f. 266.

34. Jácara nueva a san Pedro (s. XVII): «Oigan, oigan, escuchen, reparen, atiendan...», ff. 268-269v.

35. A la traslación de la cabeza de santo Tomás de Villanueva (s. XVII): «El cielo en dar, cual vos, diestro....»; ff. 270-271v.

36. [Poema (s. XVIII)]: «Celos ha dado, señores...», f. 272.

37. Poema en italiano, a Carlos IV, f. 273. 
38. Poemas varios (s. XVIII); ff. 274-317.

- A la condesa de Oñate. Soneto: «Si a imperio temporal, feudo forzoso...», f. 274.

- A una dama de palacio: «Amo solo por amar...», f. 275.

- Letras místicas para pedir agua a Dios: «Agua, Dios mío...», f. 276.

- Coplas del asunto de la gran pasión de don Bartolomé [ilegible] con el conde de Montijo: «Te tengo por muy prolijo...», f. 278.

- A la temprana muerte de una dama: «De mi intrépido dolor ciego el discurso...», f. 280.

— «Es mi vestido de lana de muy diversos colores...», f. 282.

- Habiendo picado a una dama un mosquito en la boca: «Si atrevimientos castigas...», f. 283-284v.

- Excma. Señora: «Víspera de Navidad...», f. 285.

- Ayes lastimosos que da la ciudad de Sevilla: «Ay, desgraciada Sevilla...», f. 287.

- A un emperador romano. Octavas: «Tesalónica ya hace, y con la ira...», f. 289 (también en f. 325).

- Habiendo pasado un galán cinco veces no la hizo sino dos cortesías. Décima: «Si paso por junto a vos...», f. 289.

- A una vieja que se engreía mucho. Romance: «Clori, siempre que te encuentro...», f. 289v (también en f. 326).

— «Fue, Lisis, tu crueldad...», f. 291.

— «Qué hará, Amarilis divina...», f. 293.

- Contra la lista de los chichisbeos y su Autor: «Mascarón andaluz, cerdo indecente...», f. 295.

— Décimas: «Amante pío y leal...», f. 296.

- Soneto: «Culpa la muerte fue que hizo la culpa...», f. 301.

- Décimas a la muerte del conde de Gages: «Qué hiciste, fatal guadaña...», f. 302.

- fallecimiento de Guerrero. Octavas: «Murió de las mujeres el Narciso...», ff. 304-304v.

— Al conde de Oñate: «Diote Oñate el real esmero...», f. 306.

— Décimas sevillanas: «Por tu mano irá mejor...», f. 308.

- Competencia que el prior de San Juan de Dios tuvo con el Rector de la Compañía de Jesús: «El gran Zabala quería...», f. 309.

- Décimas al asunto del Nuevo Decreto que ha salido sin que ninguna persona de cualesquiera grado o condición que sea, no ha destar, transitar ni quedarse a pasear en el prado viejo. $Y$ dejaron pasar al señor 
Farinelo, indigno de cargos de república, con capa y sin ella. Décima: «Ministro de gran celo / a quien nada se le escapa...», ff. 311-313.

— Minuete nuevo: «Corte halagüeña...», f. 315.

- A la señora Vicenta Erando. Décimas: «Hermosa deidad triunfante...», f. 317 .

39. Poema (s. XVII). Comienza: «A v. e. refiero de ayer una colación...». Acaba: «D. Francisco de Castro, por mar y por tierra», f. 321.

40. Poesías (s. XVIII):

— «Es como uva [?] sin pan...», f. 323.

— «Aun la dulzura viste de furor...», f. 325.

— Octavas: «Tesalónica ya hace y con la ira...», f. 325 (también en f. 289).

- Décimas: «Si paso por junto a vos....», f. 325v.

- A una vieja que se engreía mucho. Romance: «Clori, siempre que te encuentro...», f. 326 (también en f. 289v).

— «Observo de mi garita...», f. 327v.

— «Entre dos montes estamos...», f. 329.

— «Estás, rosa peregrina...», f. 331.

- Pasquín de «Instrucción general para que sea facilísimo tu gobierno, Ahumada»: «No haya en la ciudad Aguirre, / ni Zevallos en la Iglesia...», f. 333.

41. E. X. de O., abogado de esta Corte: Disertación sobre el origen de la Siete Partidas (1784), [prosa], ff. 335-366.

42. Égloga en tercetos: La égloga de Damón y Ergasto (s. XVI): «Déjame estar, Ergasto, que ni veo...», ff. 367-370.

43. Poemas y textos en prosa (s. XVIII); ff. 372-377:

- A la vista de un cuadro de la Anunciación dijo Francisca, de repente, de 16 años, con forzado pie, la siguiente décima: Pie: «La luz te ofrece María», «Ciertamente es de admirar...», f. 372.

- Otra de Francisco Josef en respuesta de la anterior: «Decreta Dios la fineza...», f. 372v.

— Otra de D. Diego Rejón: «Si así empiezas, llegarás...», f. 373.

- Carta en prosa de un marido (M. Ventura) a su mujer, en que le envía unas seguidillas: «A esas, pues, mis señoras...», f. 373. 
— Carta en prosa, que contiene la seguidilla: «Pues te manda, señora...», f. 376 ;

- Otra carta en prosa del mismo, que remite unas seguidillas: «Las penas que me afligen...», f. 377.

44. Poema (s. XVIII): «Admirable el criador». Más abajo se dice que «Villalobos y Medrano glosaron opuestamente, / el uno místicamente / y el otro por lo profano», f. 378.

45. Poema (s. XVIII): «Mucha flor de fantasías...», ff. 379-380.

46. Poema (s. XVIII): Siendo comisario ejecutor del ocho por ciento el inquisidor don Pascual de los Herreros se hizo la siguiente redondilla: «Para clavar ambos cleros...». Comienza la glosa: «En el Reino de Aragón...», f. 381.

47. Poema (s. XVIII): A la compañía de Josef Parra: «Parra, a todos te prefieren...", ff. 383-384.

48. Poema (s. XVIII): «Bello modo de alabarte...», f. 385.

49. Poema (s. XVIII): «Conozco, Lisi, el encanto...», ff. 387-388.

50. Poema (s. XVIII): «En años tan deseados...» [alude a la villa de Morata], f. 389 .

51. Poema (s. XVIII): «Amor, honor y poder...». Firma y rubrica un tal Antonio; ff. 391-392.

52. Poema (s. XVIII). En asunto del separamiento y nulidad del matrimonio de doña María Catalina de Albalá: «A todos hago saber...», f. 393.

53. Poema (s. XVIII): «Qué hará, Amarilis divina...», ff. 395-396.

\section{Volumen 80}

Folios 1-149

1. Juan Baptista Enríquez, Sonetos en la muerte del reverendísimo padre maestro Fr. Nicolás Baptista (1663). Impreso, 2 hs., ff. 1-2. 
2. Poema de fray Bernard Gentilis dedicado a don Martín de Angullo [texto en latín] ms., ff. 3-6v.

3. Villancico religioso y coplas. A san Francisco de Borja (s. XVII): "Angélicas escuadras...», f. 7; para el tiempo de alzar: «Esferas que giráis...», f. 8.

4. Carta jocosa de un académico a otros [prosa]. Incluye versos, que empiezan: «Qué tiene de hoja de lata...», ff. 9-10v. Incluye al final la fecha y lugar: Madrid, 22 de abril 1732.

5. Poesía religiosa de varios autores [parece una justa literaria sacra] (s. XVII). Comienza: Hermano Antonio Navarro: «Pues Jesús hoy nasce amando...», ff. 11-16.

6. Quintillas (s. XVIII): «A considerarte llego...», f. 18-18v.

7. Poema burlesco al comediante Vela con motivo de una corrida de toros (¿s. XVII?), ff. 19-21. Comienza: «No es comedia el ver a Vela...».

8. Poemas varios a la duquesa de Arcos (s. XVIII): «La duquesa de Ar$\cos \ldots »$, ff. $22-27$.

9. Poesías, segunda mitad del xvII [Motes de damas y caballeros]: «Riesgos teme mi barca...», ff. 31-33.

10. Poemas varios relacionados con la marquesa de Astorga (s. XVIII). «Don Antonio Correa...», ff. 35-4lv.

11. Celebrando los suaves números, Francisca de Castro cantó (s. XVIII): «Cuando derramas en quejas...», f. 42-42v.

12. Décimas lacónicas contra calmucos antiguos y modernos (1745): «Comedia la vida humana...», ff. 44-45 y 49-50 [sobre Enrique VIII de Inglaterra y los Estuardo. Es el texto que figura, impreso, en el volumen 79.6].

13. Poema con dibujos de una real corona (s. XVIII), ff. 46-47.

14. Poema con música a la marquesa de Astorga (s. XVIII): «Hoy a su excelencia intento...», f. 48-48v. 
15. Poemas varios (s. XVIII); comienzan: «Rendido, humilde y postrado...», f. 51 ; «Dama que no tiene punto...», ff. 51-53.

16. Profecías de Pero Grullo (s. XVII). Comienza: «Letor, cualquiera que seas...», ff. 54-55.

17. Miguel Ferrés y Valls: Píntase la festa dels bous de Chanca, en lengua valenciana (c. 1665). Redondillas: «Señores, que le pinte els bous...», ff. 57$59 \mathrm{v}$.

18. Carta (1772). Cartas y billetes a varios asuntos (s. XVIII) [prosa], f. 61.

19. Poemas varios (s. XVIII), ff. 62-75:

— «Bellísima flor de lis...», f. 62.

— «Córdoba, la no bastante...», f. 62v.

— «Excelentísimo duque...», f. 63v.

- Décimas con motivo del traslado del conde de Trastámara: "Señorito venerado...» (aparece la firma del presbítero Miguel Hurtado Arciniega), ff. 65-67v.

— «Aquel día, mortales...», ff. 68-69v.

— «Viendo, pues, lo que te quiero...», ff. 70-71.

— Soneto: «En hora buena logre tu ventura...», f. 72.

- Al Excmo. Señor Conde de Altamira como Alférez Mayor de la coronada villa de Madrid. Décimas: «Fue vuestra casa mansión...», ff. 73-74.

- Epitafio a la muerte del Excmo. Señor Conde de Altamira; Soneto: «Yace, pero no yace, en un pie solo...», f. 75 .

20. Poemas a los marqueses de Astorga, sobre todo de don Francisco de la Torre y Sevil (s. XVII), ff. 76-108.

— «Príncipe, a vuestra clemencia...», f. 76.

— «Hoy consagra a vuestra clemencia...», f. 77.

— «Ya en otra borrasca fiera...», f. 79.

— «Dijo un ingenio excelente...», f. 79.

— «En la plaza no capaz...», f. 79v.

— «Desde Orán con singular...», f. 81.

— «Oigan del marqués, marqués...», f. 84.

— «Un romance, gran marqués...», f. 84 . 
— «Hoy, señor, que en vuestra gracia...», f. 85.

— «Ya, señor, llega mi ingenio...», f. 88.

— «Entras, señor, y animas cuanto luces...», f. 92.

— «Ya, señor, llega mi ingenio...» (copiado de otra mano), f. 94.

— «Puñal y plomo que a Valencia infama...», f. 101.

— «A Valencia te conduces...», f. 102.

— «Yo, señor, que escribir suelo...», ff. 103-108.

21. A la marquesa de Astorga (s. XVIII); ff. 109-117v:

— «Honras, diademas, cetros, laureles...», f. 109.

- De D. Francisco Antonio Fernanz Saavedra. Letras al cumplimiento de años de la marquesa de Astorga: «Del día más alegre...», f. 111.

— De Manuel Josef Osorio Ponce de León: «Que es simpatía, es amor...», f. $117 \mathrm{v}$.

22. Descripción de las fiestas que los vecinos de la villa de Morata celebraron en obsequio del Excmo. Sr. Marqués de Astorga (s. XVIII), ff. 119-126. Incluye el poema que comienza: «La villa de Morata esclarecida...», f. 119v.

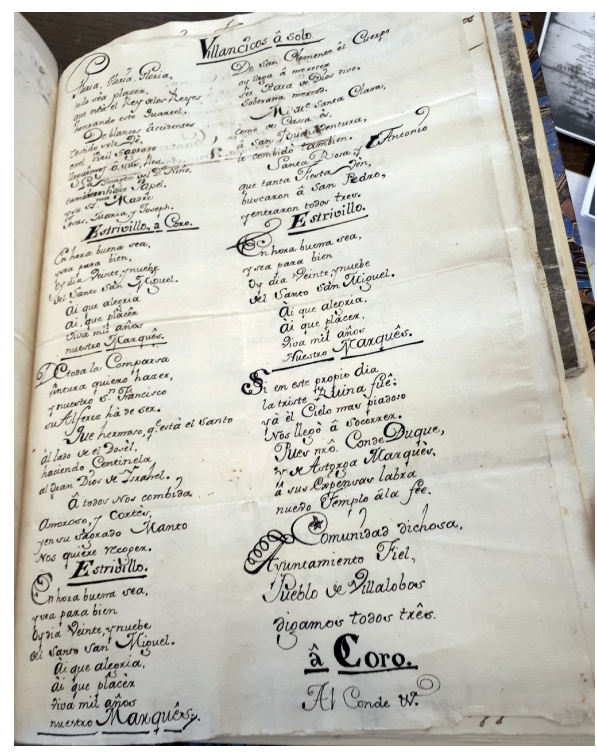

23. Villancicos que se cantaron en la Función de la Colocación de el Santísimo en la Nuestra Iglesia de el Convento de Nuestra Madre Santa Clara de 
Villalobos, edificada a expensas del Excmo. Señor Marqués de Astorga, Patrono de nuestra Iglesia y Convento. Año de 1771; ff. 127-128:

Recitado: «Oh tú, aquel sobre todos eminente...», f. 127.

Aria: «Pueblo dichoso...», f. 127.

Villancicos a solo: «Gloria, gloria, gloria...», f. 128.

24. Poesías varias a los marqueses de Astorga (s. XVIII); ff. 129-132v.

— Décimas: «Gran señor, un desvalido...», f. 129.

— «Quien mira por el consuelo...», f. 131.

— «Aunque el objeto regio causa tanto...», f. 132.

25. Poesía con dibujo de una flor entre espinas: «Viste la blanca azucena...», impresa; (¿siglo XVII?) f. 134.

26. Escrición cronológica (1668). Poesía. Impreso, 2 hs. Comienza: «Carolo II rege et Marianna Regina...», ff. 137-139.

27. Poema (s. XvIII): «Esteban Méndez de hecho...», ff. 140-144v.

28. Em louvor de Domingos Mombelli no dia do seu beneficio 2 de Dezembro de 1804 no Real Theatro de S. Carlos. Soneto: «Se da scena ao poder se tem quebrado...». Impreso [en portugués; retrato de Mombelli en fol. 147], ff. 146-147.

29. Cartel anunciador de la comedia La virtud consiste en medio, ff. 148149. 